\title{
A criatio, uma outra dimensão de fidelidade no contexto de ascensão da dinastia de Avis (1384)
}

\author{
Fátima Regina Fernandes ${ }^{1 *}$ \\ ${ }^{1}$ Universidade Federal do Paraná, Curitiba/PR - Brasil
}

\section{RESUMO}

A relação de criatio estabelecida desde a infância é marcada pela informalidade jurídica, mas constitui um vínculo estreito e duradouro. Face a contextos de grande instabilidade de partidarismos, seriam instrumentos úteis às lideranças emergentes frente a seus opositores. Assim, no recorte de 1383-1385, em Portugal, a ascensão do Mestre de Avis como alternativa política dependeu, num primeiro momento, do apoio daqueles jovens que foram criados por ele ou por seus aliados na composição de sua sociedade política. Um tema cujo desenvolvimento foi possível graças ao recurso à prosopografia aplicada ao manuseio dos materiais documentais como a Chancelaria régia, a Crônica régia joanina, assim como outra documentação complementar e avulsa, sem dispensar o suporte da historiografia, clássica e mais atual, que trata da referida ascensão avisina.

Palavras-chave: Dinastia de Avis; prosopografia; criatio; fidelidade; crise 1383-1385; Cerco de Lisboa.

\section{The criatio, another dimension of fidelity in the context of the ascension of the Avis dynasty (1384)}

\begin{abstract}
The relationship of criatio, established since infancy, is marked by juridical informality but constitutes of a strict and long-lasting bond. Within the context of great political instability and partisanship in Portugal during the 1380s, these relationships would have been useful instruments to the emerging leadership in the fight against its opponents. Thus, during the period from 1383 to 1385 , the rise of the Master of Avis as a political alternative depended, first and foremost, on the support of the young people who were bound to him or his allies
\end{abstract}

DOI: http://dx.doi.org/10.1590/2237-101X02104402

Artigo recebido em 9 de março de 2019 e aceito para publicação em 20 de julho de 2019.

* Professora da Universidade Federal do Paraná / Departamento de História, Curitiba/PR - Brasil. E-mail: fatimaregi62@gmail.com. ORCID: https://orcid.org/0000-0002-4747-8146. 
in the composition of his political society. Exploring this theme is possible thanks to the tools of the prosopography - which can be applied to documentary materials such as the Royal Chancellery, the Chronicle of Joanine, and other special documentation - as well as the classical and contemporary historiography, which covers the rise of the Avis Dynasty. Keywords: Dynasty of Avis; prosopography; criatio; fidelity; crisis of 1383-85; Siege of Lisbon.

\section{La criatio, una otra dimensión de fidelidad en el contexto de ascensión de la dinastía de Avis (1384)}

\section{RESUMEN}

La relación de criato establecida desde la infancia es marcada por la informalidad jurídica, pero constituye un vínculo estrecho y duradero. Frente a contextos de gran inestabilidad de partidarismos serían instrumentos útiles a los liderazgos emergentes frente a sus opositores. De esta forma, en el recorte de 1383-5 en Portugal, la ascensión del Maestre de Avis como alternativa política dependió, en un primer momento, del apoyo de aquellos jóvenes que fueron criados por él o por sus aliados en la composición de su sociedad política. Un tema, cuyo desarrollo fue posible gracias al recurso de la prosopografía aplicada al manoseo de los materiales documentales como la Cancillería real, la Crónica real joanina, así como otra documentación complementar dispersa, sin dispensar el soporte de la historiografía clásica y más actual que trata de la referida ascensión de Avis.

Palabras clave: Dinastía de Avis; prosopografía; criatio; fidelidad; crisis 1383-85; Cerco de Lisboa.

\section{Introdução}

A criação ou criatio constitui uma prática que se dissemina sem estar presa a uma categoria jurídica rígida no mundo medieval e, portanto, apresenta algumas nuances conforme a condição dos envolvidos nessa vinculação. A condição daquele que foi sujeito à criatio foi definida por Viterbo como

aquelle, que fora creado na casa, ou companhia de alguém, sem mais salario, nem obrigaçâo de servir, senão conforme aos da sua qualidade. E assim: meu Criado: era o que eu criei, ou mantive desde pequeno em minha casa, e debaixo da minha inspecção, ou doutrina. E o mesmo se dizia da Criada (VITERBO, 1962-1965, t. I, p. 318). 
Rita Costa Gomes (1995, p. 181-183) afirma que essa relação seria precedida de um vínculo natural entre as duas partes que estaria para além da consanguinidade, ainda que, em alguns casos, complementasse e aprofundasse o vínculo vassálico. A criatio gerava, assim, um parentesco artificial que envolveria, segundo Leontina Ventura (1992, v. 2, p. 240-241), relações de natureza pessoal e política, criando círculos de vinculação mais estreitos do que os da vassalidade, e manifestando, nas palavras de José Mattoso (1985, v. 1, p. 224-225), um caráter doméstico, privado da vassalidade. Amizade e serviço, dois eixos fundamentais dessa sociedade medieval que são refletidos nesta relação de criatio, assim definida por Ventura:

Esta afectividade fundada quer na criatio pelo Rei (clientulus, alumnus), quer na criatio do Rei (conlazus) serve como justificação para certos cargos. Manifesta a associação da functio, do serviço régio à amizade, dando à relação entre o oficial e o soberano uma tonalidade "familiar". A criatio de cavaleiros na casa do príncipe representa, por isso, a esperança de uma carreira na Corte, ou, pelo menos, o estabelecimento de relaçóes vantajosas para o seu futuro (VENTURA, 1992, v. 2, p. 241).

Portanto, parece-nos que, enquanto prática, a criatio não estaria vinculada a um juramento de fidelidade específico, sendo, inclusive, anterior à sua possível aplicação pela idade do beneficiado. Mas, por ser uma relação empírica, quotidiana e privada, teria uma força de conexão e proteção mais estreita e duradoura do que aquela que vinculava um vassalo a um senhor. $\mathrm{O}$ que não invalidava a possibilidade de futura vassalização do jovem criado em sua Casa, conforme a sua posição sociopolítica, assim como outros benefícios potenciais adjacentes à condição de criado de um senhor poderoso.

Quanto à composição sociopolítica desse universo de criados, Hilda Grassotti nos alerta sobre a sua natureza eclética e desigual:

Os reis frequentemente faziam mercês a pessoas que qualificavam como homens de sua criação e, dentre eles, incluíam desde servidores de condição inferior até o porta-estandarte de sua hoste [...].

Se reis, infantes, magnates, prelados e abades criavam assim, junto a eles, desde futuros capitães, alferes e bispos até falconeiros, balesteiros, despenseiros, camareiros, forneiros... não podemos nos surpreender que os ricos homens criassem em suas casas filhos de fidalgos e cavaleiros mesmo aqueles que não pertenciam à nobreza: de alguns dos quais faziam seus vassalos. Escrevi sobre alguns porque outros dos criados por reis e ricos-homens e naturalmente também por infançóes, prelados e abades por sua inferior condição social não eram admitidos senão excepcionalmente nas fileiras da vassalagem daqueles que os criavam. Observemos que muitos dos criados anteriormente citados são chamados pelos reis, nobres e prelados que os criaram não como seus vassalos, mas como seus homens: e aparecem desempenhando serviços 
domésticos próximo a eles: à frente de sua dispensa ou de sua câmara, cuidando de seus falcôes, integrando a sua guarda pessoal... ou exercendo ofícios incompatíveis, como o de forneiro, com sua pertença ao grupo vassalático do rei ou de magnate que o qualificava como seu homem ou seu criado (GRASSOTTI, 1969, p. 349-351). ${ }^{1}$

Assim, a partir daqui, em benefício da concisão expositiva, nos referiremos àqueles beneficiados com a criatio pela simples designação de criados de(o), sem prejuízo da precisão conceitual, entendendo se tratar de um universo que contempla desde nobres como indivíduos de outra condição, criados por alguém de quem se tornam devedores de natural fidelidade. Uma tarefa que importava em grande impacto financeiro para aquele que cria outrem, condição que naturalmente limitaria o universo dos potenciais criadores aos membros da Casa régia e indivíduos suficientemente poderosos para tanto.

A preocupação com os criados surgiu do manuseio documental da Chancelaria de D. João I em busca do conhecimento da sua primeira sociedade política no contexto dos conflitos que marcaram o reino português entre 1383-1385. Dentre outras categorias, a dos criados destaca-se nas cartas de doação desse recorte cronológico, as quais implicavam na transferência de bens de traidores confiscados a fiéis da causa portuguesa. A metodologia selecionada para análise dos documentos é a prosopográfica, que tem se atualizado com grande pujança nos ambientes historiográficos e sido aplicada em muitos cenários documentais e cronológicos, dentre eles, com grande eficácia, o contexto medieval ibérico (AUTRAND, 1986; AURELL, 2001; MOXÓ Y ORTIZ DE VILLAJOS, 1969; GERBET, 1989; VENTURA, 1992; GENET, 1999; HOMEM, 1990; GOMES, 1995; ALMEIDA, 2009; HEINZ, 2006; FERNANDES, 2003). Demonstra-se útil à proposta desenvolvida nesta investigação sobre a importância dos criados neste recorte, principalmente por propiciar a definição do perfil de criado a partir de casos concretos contextualizados e comparados entre si, tornando mais específica a avaliação da contribuição dos mesmos junto ao Infante D. João, Mestre de Avis, num contexto de escassos apoios e legitimidade 2 . Permite-nos, ainda, avalizar a eficácia do

\footnotetext{
${ }^{1}$ No original: "Con frecuencia los reyes hicieron mercedes a gentes a quienes calificaban de hombres de su criazón, y entre ellos incluyen desde servidores de condición inferior hasta el portaestandarte de su hueste (...) Si reyes, infantes, magnates, prelados y abades criaban así junto a ellos desde futuros capitanes, alféreces y obispos hasta halconeros, ballesteros, despenseros, camareros, horneros... no puede sorprender que los ricoshombres criasen en sus casas hijos de hidalgos y caballeros y aun de quienes no pertenecían a la nobleza: de algunos de los cuales hacían luego sus vasallos. He escrito de algunos porque otros de los criados por reyes y ricos-hombres y naturalmente también por infanzones, prelados y abades, por su inferior condición social no eran admitidos si no excepcionalmente en las filas del vasallaje de quienes los criaban. Observemos que muchos de los criados antes citados son llamados por los reyes, los nobles o los prelados que los criaron no sus vasallos sino sus homines; y que aparecen desempeñando cerca de ellos servicios domésticos: al frente de su despensa o de su cámara, cuidando de sus halcones, integrando su guardia personal...o ejerciendo oficios incompatibles, como el de hornero, con su pertenencia al grupo vasallático del rey o del magnate que le calificaba de su hombre o de su criado".

${ }^{2}$ Este trabalho utilizou a base de dados DataClio elaborada por Daniel Augusto Arpelau Orta e Luiz Orta, disponível em: http://www.infoclip.com.br/DATACLIO/SrvPesquisa?action=obterURL\&codigo=7.
} 
critério de fidelidade e serviço que congregaria este universo de fiéis, tão distinto e ao mesmo tempo tâo coeso, pela criatio, constituindo uma rede de vinculação que conviveria de forma pacífica com a linhagística e vassálica nessa realidade tardo medieval ibérica.

Nos casos observados em nosso recorte trataremos dos indivíduos que são identificados como criados num contexto anterior à ascensão de D. João I como rei. Filho natural do rei D. Pedro I de Portugal e Mestre da Ordem de Avis, acompanharia os eventos que envolveram a vida e principalmente a morte de seu irmão, o rei D. Fernando, após a qual se instala uma crise dinástica no reino. O Mestre de Avis seria projetado como sucessor de seu irmão entre 1383 e 1385 quando é eleito rei, em meio a uma guerra contra seu concorrente, o rei castelhano Juan I Trastâmara e seus apoiantes em Portugal (MATTOSO; SOUSA, 1993).

Recortamos cronologicamente os documentos da Chancelaria régia de D. João I, desde 6 de dezembro de 1383, quando do levante e imediato alçamento popular do Mestre como Regedor e Defensor do Reino em 15-16 de dezembro de 1383 até 31 de agosto de 1385 quando já teriam se realizado as Cortes de Coimbra, de abril de 1385, que o reconheceriam como rei, assim como a Batalha de Aljubarrota de agosto, que confirmaria essa situação no campo de batalha (FERNANDES, 2018).

De um total de 205 documentos contidos nesse recorte cronológico, localizamos 31 fontes, entre janeiro de 1384 e janeiro de 1385 , que se relacionam à condição de criados e, com exceção de um, todos os demais são exarados da cidade de Lisboa, constituindo 15,12\% do universo documental disponível na Chancelaria régia de D. João I, relativo ao lapso proposto nesta investigação. Observamos que as açôes que se desenrolam no ano de 1384 estarão diretamente ligadas às decorrências da preparação e resistência portuguesa ao cerco castelhano sobre Lisboa, o qual se inicia em 29 de maio e permanece até 3 de setembro de 1384, quando da partida de D. Juan I Trastâmara rumo a Torres Vedras e, na sequência, Castela. As escaramuças e confiscos se mantêm, ainda que com menor intensidade, até 28 de outubro de 1384, quando a frota castelhana parte de Lisboa (VIEGAS, 1984, p. 121; 134). Hostilidades que promoviam uma forte limitação da deslocação do Mestre de Avis, líder militar e político da resistência, mas que também o projetavam simultaneamente à cidade, convertendo ambos em referências de oposição às alternativas castelhanas e portuguesas, como bem nos ensinam Marcello Caetano (1985) e Humberto Baquero Moreno (1988). Daí ser compreensível que dentre as várias iniciativas visando à defesa da cidade encontremos a concessão à autarquia lisboeta de uma carta de privilégios datada de $1^{\circ}$ de abril de 1384 , na qual o Mestre, reconhecido como Regedor do reino pelos mesteirais e moradores de Lisboa, fazia importantes concessões em questóes de interesse econômico e fiscal dessas categorias da municipalidade. E, com isso, segundo Caetano (1985), tentava granjear o apoio da burguesia da cidade ainda insegura quanto às partidarizaçóes a tomar diante de um panorama de incertezas e divisóes internas como aquele enfrentado pelo reino português. Ademais, indiretamente, a manifestação concessiva do Mestre indicava que nesse movimento de resis- 
tência havia um centro de poder minimamente ativo e disposto a conquistar apoios internos de outras categorias para além da nobreza.

Percebemos algumas nuances formais dos documentos que podem ter relação com essas contingências contextuais da resistência, como nos documentos anteriores ao cerco, de fevereiro a maio de 1384, o predomínio de documentos coletivos em que conjuntos de criados do Mestre são beneficiados com bens de vários confiscados simultaneamente sob a justificativa vaga de desserviço. Assim, a 20 de março, um documento que envolve quatro moradores de Portalegre, Castelo de Vide e Monforte como confiscados, resulta no benefício de dois criados do rei ${ }^{3}$ e, a 10 de maio, dois moradores de Campo Maior são confiscados em benefício de outro criado do rei ${ }^{4}$. Certamente o Mestre estaria constrangido pela urgência em angariar apoios e pouco cioso da formalidade de individualização das concessóes e confiscos. Conforme se aproxima o fim do cerco, observa-se uma nova tendência de intensificação das concessôes a criados, agora certamente ligada à expectativa desses apoiantes em serem beneficiados antes da libertação e dispersão dos resistentes de Lisboa e, a partir daí, a tendência que se observa é a de documentos de benefício e confisco individuais. Além disso, observamos que a justificativa dos confiscos se apresenta mais elaborada nessa fase dos eventos, apoiando-se na condiçấo absentista do traidor, que, segundo os documentos, andaria em desserviço juntamente com o rei de Castela. Estaria o Mestre mais seguro de suas concessóes, especialmente a criados que já teriam demonstrado seu apoio durante o cerco.

Destacamos que o único documento desse recorte e problemática dos criados do ano de 1385, datado de 12 de janeiro, foi exarado do cerco de Torres Vedras, onde o Mestre permaneceria até fevereiro a caminho das Cortes de Coimbra (LOPES, 1991, p. 386-388; MORENO, 1988, p. 19)5. Inicia-se como uma transferência de bens de um pai já falecido a um criado do Mestre e cavaleiro da Ordem de Santiago ${ }^{6}$, mas se enquadra no conjunto geral dos documentos por beneficiar um nobre criado pelo Mestre. Além disso, esse benefício certamente implicaria o confisco de indivíduos que teriam usufruído os bens envolvidos, ainda que não sejam mencionados no documento.

Assim, a partir desses critérios acima definidos, três eixos de análise foram estabelecidos: o primeiro, o dos indivíduos criados diretamente pelo Mestre e/ou Ordem de Avis que receberiam os bens de traidores da sua causa, não identificados como criados por outrem. Um segundo eixo de análise tratará daqueles que foram criados do rei anterior, D. Fernando, beneficiados pelo Mestre em contrapartida de seu apoio. Mas também englobará os indi-

\footnotetext{
3 Álvaro Rodrigues e Álvaro Vasques (Arquivos Nacionais/ Torre do Tombo. Chancelaria de D. João I, 1.1, f.7v. A partir daqui, essa fonte será apresentada como Chanc. DJI, seguida do livro e fólio correspondente.

${ }^{4}$ Rui Vasques de Elvas (Chanc. DJI, 1. I, f. 10v).

${ }^{5}$ Nesta investigaçấo, consideramos a natureza e proposta das Crônicas régias com forte acento ideológico de legitimação distintas dos documentos chancelares, além de redigidas num contexto posterior aos eventos, mas, ainda sim, bastante úteis em termos contextuais, fornecendo suporte à nossa pesquisa nesse âmbito contextual (vide ainda a esse respeito, FERNANDES, 2012).

${ }^{6}$ Fernão Peres Churrichão a seu filho Álvaro Peres Churrichão (Chanc. DJI, l. I, f. 75v).
} 
víduos criados pelo rei morto que se tornaram opositores do Mestre e, portanto, cujos bens beneficiariam os servidores deste. Um terceiro eixo tratará dos homens criados por aliados ou inimigos de D. João e o destino de seus bens. Análise que deve ser acompanhada com o quadro e mapa em anexo.

\section{Os homens criados pelo Mestre e/ou Ordem de Avis e suas fidelidades}

O primeiro eixo seria o dos criados pelo Mestre e/ou Ordem de Avis que receberiam bens de traidores que não são identificados como criados por outrem, constituindo um núcleo mais próximo de apoiantes do líder da resistência ao inimigo.

Destaque-se, aqui, que o próprio Infante fora entregue, por ordenamento de seu pai, o rei D. Pedro I, para ser criado, na primeira infância, por Nuno Freire de Andrade, Mestre da Ordem de Cristo. ${ }^{7}$ Por intercessão de seu criador, aos sete anos de idade, o Infante bastardo obtém do rei a concessão do Mestrado da Ordem de Avis, onde completaria a sua formação, como seu Mestre (SOUSA, 1735, t. III, p. 6-7) ${ }^{8}$. Mas onde também experimentaria por si mesmo ou por simbiose a condição de criado na Casa da Ordem, o que certamente o tornaria sensível a outros que tivessem tido essa mesma experiência, inclusive sob sua própria criação, como veremos nos casos a seguir.

Inicia-se esta série com um documento de 18 de fevereiro de 1384, no qual encontramos o benefício a Vasco Eanes, criado pela Ordem de Avis e morador dessa localidade que recebe bens em Évora de traidores da causa portuguesa ${ }^{9}$, manifestando concessões em região sensível à invasão castelhana, pelo Infante que encontrava-se em Lisboa até pelo menos setembro, e de onde todas as outras cartas nesse ano são exaradas. No mês seguinte, em março, inicia-se um primeiro pico de transferências de bens devido aos preparativos de resistência ao cerco iminente, iniciado com o benefício a 2 de março a um criado do Mestre, Rodrigo Eanes Barvudo, com bens em Almada ${ }^{10}$. Em outra documentação, onde esse indivíduo não aparece especificamente identificado como criado, será também objeto de benefícios expressivos o reguengo de Colares em detrimento de João Fernandes Andeiro, já morto, com data de 7 de janeiro, o que transforma este, cronologicamente, no primeiro documento deste eixo ${ }^{11}$. Existe, ainda, uma outra referência a um Rodrigo Eanes, também criado do Mestre, beneficiado a

\footnotetext{
${ }^{7}$ Ainda que Fernão Lopes, na Crónica de D. Pedro I (1965, p. 9; 195), fale de um cidadão de Lisboa, Lourenço Martins da Praça, que teria tido função semelhante (ver também SOUSA, 1735, t. III, p. 2-5).

${ }^{8}$ Trajetória que sua máe, Teresa Lourenço, acompanharia de perto, pois no ano seguinte à sua investidura na Ordem, em 1365, sua mãe receberia ampla doação régia de bens em Avis (Arquivos Nacionais/ Torre do Tombo, Chancelaria de D. Pedro I, I. I, f. 112. A partir daqui, essa fonte será apresentada como Chanc. DPI, seguida do livro e fólio correspondente.

${ }_{9}^{9}$ João Domingues Falardo e filho, ambos moradores da dita vila (Chanc. DJI, l. I, f. 1v).

${ }^{10}$ De Martim Eanes, Comendador de Pedroso e irmão (Chanc. DJI, l. I, f. 1v).

${ }^{11}$ Chanc. DJI, l. I, f. 22v-23.
} 
13 de março com bens de um morador de Santarém, podendo tratar-se do mesmo indivíduo acima referido ${ }^{12}$. Um criado beneficiado em três documentos pelo seu criador no entorno de Lisboa, onde, ao que tudo indica, os dois se encontravam. Situação semelhável à de outro criado do Mestre, João Gonçalves, que, a 10 de março, receberia bens em Santarém ${ }^{13}$.

A 20 de março dois outros criados do Mestre, Álvaro Rodrigues e Álvaro Vasques, ambos moradores em Portalegre num dos documentos coletivos mais ricos deste recorte, seriam beneficiados com bens de quatro moradores de Portalegre, Castelo de Vide e Monforte, traidores da causa do Mestre ${ }^{14}$. Num contexto mais amplo observamos que neste mês de março de 1384 foi quando Pedro Alvares Pereira, Prior da Ordem do Hospital que defendia as pretensóes de D. Juan I Trastâmara, cerca Portalegre, regiáo de tradicional assentamento dos Pereira, promovendo estragos nos termos da vila (LOPES, 1991, p. 166). Pelo menos um dos confiscados, Fernão Paes Engreiros, morador de Portalegre, era seu vassalo ${ }^{15}$ e deve ter tido protagonismo nesses ataques à região de histórica influência da linhagem do Prior. Em resposta a essas açôes, numa iniciativa dos moradores da vila, o castelo seria recuperado e entregue ao Mestre (LOPES, 1991, p. 87). Esse é, certamente, o mote que justificaria o benefício dos criados do Mestre, Álvaro Rodrigues e Álvaro Vasques. Mesmo remotamente, a vinculação entre um criador em Lisboa e seus criados no Alto Alentejo promovia resistência substantiva aos seus inimigos ${ }^{16}$.

Voltando a Lisboa, vemos que, a $1^{\circ}$ de abril, os mesteirais e moradores de Lisboa recebem a motivadora carta de privilégios pelo apoio da cidade à sua causa. O cerco ainda não fora imposto, mas a insegurança grassava pelas regióes fronteiriças por onde entrava o rei castelhano, daí que se multipliquem as cartas que envolvem o confisco de bens daqueles que haviam dado conselho de rendição e entrega dos castelos das vilas onde residiam ao inimigo invasor. Uma opção que manifestava a busca pela preservação física e material dos chamados traidores num contexto de incertezas de partidarismos, mas que também aqui encontrariam resistências de criados do Mestre que viviam nessas localidades atingidas. Assim, no mesmo dia $1^{\circ}$ de abril, D. Joáo beneficiaria Aires Martins, seu criado e escudeiro, com bens de moradores da Guarda que haviam aconselhado, em janeiro desse ano, a entrega da cidade fronteiriça ao rei de Castela ${ }^{17}$ com apoio do bispo beirão. A resistência interna a essa entrega

\footnotetext{
${ }^{12}$ Bens de Lopo Rodrigues Partainho (Chanc. DJI, 1.1, f. 2 e v).

${ }^{13}$ Confiscados a Afonso Eanes de Alenquer (Chanc. DJI, l.1, f. 6v).

${ }^{14}$ Bens de Fernão Paes Engreiros, Pero Fundeiro, Afonso Rodrigues Bortoloso e Lourenço Gonçalves (Chanc. DJI, l.1, f. 7v).

${ }^{15}$ Arquivos Nacionais/ Torre do Tombo. Chancelaria de D. Fernando, 1. II, f. 99 e v e l. III, f. 59. A partir daqui essa fonte será apresentada como Chanc. DF, seguida do livro e fólio correspondente.

${ }^{16}$ Já os vassalos de Pedro Alvares Pereira, após o levantamento do cerco sobre Lisboa em setembro, o acompanhariam até Castela onde seria feito Mestre da Ordem de Calatrava (LOPES, 1991, p. 328-332). Vide ainda a respeito do protagonismo de açáo desses homens de fronteira, FERNANDES, 2013 e FERNANDES, 2016.

${ }^{17}$ Os confiscados seriam Álvaro Eanes do Porto e Álvaro Gonçalves de Proença (Chanc. DJI, 1.1, f. 28 v; LOPES, 1991, p. 114-115).
} 
seria liderada por Álvaro Gil de Cabral, alcaide-mor do castelo da Guarda, que mantivera uma postura até então neutra diante da presença do rei castelhano ${ }^{18}$. A 6 de maio, outro seu criado, Vasco Eanes, seria beneficiado com bens, em Alter do Chão, de um tabelião que, igualmente dera conselho de entrega do castelo ao rei castelhano ${ }^{19}$. Nesses momentos, em muitos casos, as lideranças locais assumiam protagonismo da resistência e tornavam-se importantes aliados regionais do Mestre com ajuda de seus criados da regiáo.

A proximidade do inimigo aumenta o ritmo das doaçôes e respectivos confiscos, assim, a 8 de maio, Álvaro Martins, outro criado de D. João, seria beneficiado em Avis com os bens de Joáo Afonso, castelhano que perdera seus bens por estar com o rei castelhano. ${ }^{20} \mathrm{Na}$ mesma data, outro beneficiado, Diogo Esteves, também criado do Mestre recebe bens em Santarém, de um traidor que andava fora do reino ${ }^{21}$. Da mesma forma que a 10 de maio seria a vez de outro criado, Rui Vasques de Elvas, se beneficiar com bens de moradores de Campo Maior que os perderam por estar em desserviço. ${ }^{22} \mathrm{E}$, no dia 30, o criado e escudeiro do Mestre, Álvaro Peres de Avelar receberia bens em Lisboa de um traidor que andava com o rei de Castela em desserviço. ${ }^{23}$ Outro aspecto aqui observado é que neste mês de maio de 1384 aumentam as referências à ausência dos traidores de suas regióes de estabelecimento, o que manifesta claramente que a entrada de D. Juan I, com suas hostes no território português, atraía para si apoiantes portugueses, inclusive em Lisboa, onde se encontrava o Mestre e regióes de sua influência direta como Avis.

Em setembro, o cerco castelhano começava a se desfazer e, no mês seguinte, a 6 de outubro, observa-se a confirmaçáo do Mestre como Regedor, Defensor e Governador do reino (LOPES, 1991, p. 324-327) e uma ampliação dos privilégios de abril ao Concelho de Lisboa (CAETANO, 1985). Parece-nos que aumenta a confiança do Mestre, ou pelo menos a sua ousadia, pois, nesse interim, observa-se um novo frenesi de doaçôes concentradas, resultantes de confisco, agora cada vez mais de nobres. Inicia-se em 2 de setembro com o benefício a Estevão Lourenço, que, além de seu criado, era seu vassalo e aposentador-mor em detrimento dos bens de Gonçalo Vasques de Azevedo em Almada ${ }^{24}$, concessão confirmada e ampliada em instrumento de 17 de setembro ${ }^{25}$. Dessa vez o confiscado em desserviço era um nobre, Gonçalo Vasques de Azevedo, que, num contexto anterior, havia partilhado com o Mestre da hostilidade da rainha Leonor Teles e inclusive do cárcere (LOPES, 1966). Ainda em meados deste mês de setembro, outro

\footnotetext{
${ }^{18} \mathrm{O}$ castelo da Guarda fora, desde 12 de julho de 1381, do Conde Enrique Manuel de Vilhena (Chanc. DF, 1. II, f. 84) mas, desde 22 de julho de 1383, seria transferido para Álvaro Gil Cabral (Chanc. DF, 1. III, f. 77v).

${ }^{19}$ Tabelião João Vicente (Chanc. DJI, 1. 1, f. 19).

${ }^{20}$ Chanc. DJI, 1. 1, f. 61.

${ }^{21}$ Lourenço Rodrigues (Chanc. DJI, 1. 1, f. 26).

${ }^{22}$ Rodrigo Eanes e João Vicente (Chanc. DJI, 1. 1, f. 10v).

${ }^{23}$ Rui Lopes, filho de Lopo Simóes (Chanc. DJI, 1. 1, 1.1, f. 12v).

${ }^{24}$ Chanc. DJI, 1. 1, f. 72 v.

${ }^{25}$ Chanc. DJI, 1, 1. 1, f. 54.
} 
criado do Mestre, Álvaro Lourenço, recebe bens de um traidor, na Covilhã, ${ }^{26}$ e Álvaro Vasques, já referido anteriormente, receberia, a 20 de setembro, bens em Torres Vedras ${ }^{27}$, rota de passagem do rei castelhano (VIEGAS, 1984, p. 134). No dia 23 de setembro, Gonçalo Fernandes, outro seu criado, seria beneficiado na vila de Santarém em detrimento de Afonso Eanes de Arraiolos ${ }^{28}$ e, no dia seguinte, Afonso Eanes recebe bens de Fernão Rodrigues da Covilhã, que andava em desserviço. ${ }^{29}$ Nesse momento, o desconcerto causado pelo fracasso do cerco a Lisboa e a libertação da cidade promoviam uma diáspora dos apoiantes do rei invasor que até entáo tinham sido por ele atraídos e cujos bens serviriam como moeda de troca, benefício pela fidelidade ao Mestre de Avis, inclusive aos seus muitos criados.

Em documento de 12 de janeiro de 1385, observa-se o último benefício neste recorte, de um criado do Mestre, cavaleiro da Ordem de Santiago, Álvaro Peres Churrichão, com bens que pertenciam a seu pai, pelos muitos serviços que tinha prestado ao reino ${ }^{30}$. $\mathrm{O}$ beneficiado era filho de um emperegilado galego, opositor dos Trastâmara, Fernão Peres Churrichão, expulso do reino português em $1373,{ }^{31}$ e cuja responsabilidade da criação de seu filho, Álvaro Peres, parece ter recaído nos ombros do Mestre de Avis. Durante o cerco a Torres Vedras, de onde exara esse documento, D. Joáo beneficia esse seu criado, membro de importante Ordem Militar castelhana na qual pode ter ingressado por sua influência, tal como acontecera com ele na sua infância. Além disso, o nobre Álvaro Churrichão, tal como seu pai, mantinha a postura de resistência a um rei Trastâmara em território português, onde fora para tanto beneficiado, e o reinvestimento nesse patrimônio implicaria igualmente o confisco de terceiros, que, nesse interim, haviam sido seus usufrutuários, ainda que não identificados no documento.

Assim, vemos que este recorte apresenta 19 documentos dos 31 analisados no total, que cobrem o maior lapso, de 7 de janeiro de 1384 a 12 de janeiro de 1385. Os criados diretos do Mestre e da Ordem de Avis são beneficiados em detrimento de outras categorias que não criados, compondo um leque amplo de confiscados. Náo podemos mensurar, neste momento, os potenciais criados do Mestre ou da Ordem que eventualmente tenham abandonado a sua fidelidade nesse contexto, mas podemos afirmar que é substantiva a quantidade de seus criados que o apoiam, especialmente em Lisboa, no Ribatejo e em regiôes de influência da Ordem de Avis, como o Alto Alentejo. Um universo de 16 indivíduos identificados e beneficiados a partir da sua condiçáo de criados do Mestre, expostos em 19 documentos, num interstício de 12 meses, com índice de concentraçáo nos meses de março, maio e setembro de 1384, perfazendo um universo bem amplo de fiéis que deviam sua criação ao líder da

${ }^{26}$ De Fernão Peres (Chanc. DJI, 1. 1, f. 29 v).

${ }^{27}$ De Lourenço Eanes (Chanc. DJI, 1.1, f. 45 v).

${ }^{28}$ Chanc. DJI, 1. 1, f. 56.

${ }^{29}$ Chanc. DJI, 1. 1, f. 39 v.

${ }^{30}$ Chanc. DJI, 1. 1, f. 75 v.

${ }^{31}$ Seria um fiel de Fernando de Castro e matara em Castela o Arcebispo de Santiago, Sueiro Gomes de Toledo, por ordem do rei Pedro I, o Cruel e no exílio na Inglaterra continuaria a seguir João Fernandes Andeiro (LOPES, 1965, p. 184-185; LOPES, 1966, p. 221-223; RUSSELL, 1940, p. 20-30). 
resistência e o apoiavam em sua empreitada. Vejamos, agora, como se comportam aqueles que deviam a criação ao rei $\mathrm{D}$. Fernando nesse contexto conturbado e instável.

\section{Os homens criados pelo rei anterior e suas fidelidades}

Abordaremos, agora, o segundo eixo deste recorte, no qual analisaremos os criados por D. Fernando que, após o desaparecimento de seu criador e rompimento natural de seu vínculo, escolhem apoiar o Mestre de Avis e são por ele beneficiados, tornando-se seus fiéis, e aqueles que, diante da mesma situação, resolvem apoiar o rei Trastâmara, e, por isso, são confiscados e acusados de traição em Portugal. Conforme veremos, as transferências se circunscrevem ao período entre o fim do cerco de Lisboa, em setembro de 1384, que abria um ciclo de alta das doaçóes compensatórias dos resistentes ao invasor. Assim, em setembro, Fernão Gonçalves, porteiro, e Gil Fernandes, escudeiro, ambos criados por D. Fernando, seriam beneficiados em Santarém, respectivamente, em 6 e 23 de setembro ${ }^{32}$.

Em 19 de outubro, no entanto, encontramos um documento que aponta para uma situação contrária: Lourenço Fernandes, criado de D. Fernando, teria seus bens e de sua mulher, em qualquer parte do reino, transferidos a um escudeiro de D. João, por andar em companhia do rei de Castela em desserviço ${ }^{33}$. As divisóes de partidarizaçáo encontravam aqui mais uma vez um exemplo, pois, os três criados, após a morte daquele que os criara e investira, manifestam autonomia de assumirem este ou aquele lado da disputa.

Demarca-se, assim, nos três casos analisados, que as vinculaçôes de fidelidade dos criados tendiam a ser vitalícias e, portanto, revistas apenas com a morte de seu criador. Nos dois primeiros casos, os criados seriam beneficiados pela adesão, não mais como criados, mas fiéis do Mestre de Avis, e no terceiro caso a adesão a D. Juan I, um rei já alçado, redundaria no confisco de seus bens no reino português; uma aposta de futuro que devia parecer mais segura naquele momento do que a adesão à causa do Mestre.

Portanto, observamos que, neste segundo eixo, apenas três criados são mencionados em três documentos dos 31 analisados, um número inferior em relação ao conjunto anteriormente analisado, manifestando uma tendência de menor impacto de adesão dos criados do rei D. Fernando à causa de Avis, afinal, os indivíduos analisados devem representar uma fraçáo insignificante do universo de criados original do rei em vida. Com sua morte parecem hesitar em entregar a sua fidelidade a outrem, salvo os três casos mencionados neste recorte. Além disso, os documentos circunscrevem-se ao lapso cronológico de 6 de setembro a 19 de outubro de 1384, que coincide com a liberaçáo do cerco a Lisboa, o que pode manifestar uma tomada de posicionamento mais tardia desses três indivíduos em relação ao contexto quando comparados

\footnotetext{
${ }^{32}$ Com bens de Afonso Eanes e Dom Abrahão, respectivamente (Chanc. DJI, 1. 1, f. 29 e 49 v).

${ }^{33} \mathrm{O}$ beneficiado era Afonso Domingues de Saavedra (Chanc. DJI, 1. 1, f. 65 v).
} 
ao item anterior, ou talvez, uma demora do Mestre em definir a natureza das novas opçóes desses criados do último rei da dinastia de Borgonha. Avancemos, agora, para outra dimensão deste tema, alcançando a amplitude dos criados de aliados e inimigos de D. Joáo.

\section{Os homens criados pelos opositores ou aliados de Avis e suas fidelidades}

Um terceiro eixo de análise é o dos criados por antagonistas do Mestre de Avis que acompanham as forças inimigas, durante e após o levantamento do cerco, assim como o dos criados dos aliados do Mestre e os efeitos dessa condição em seus bens.

Abre-se este recorte com Vasco Gonçalves, criado do nobre João Gonçalves da Teixeira, confiscado a 30 de março de 1384 por andar em companhia de seu criador e do rei de Castela, e, por isso, seus bens em Lisboa seriam transferidos para um escudeiro do Mestre, João Gonçalves $^{34}$. Na sequência observamos uma concentração de confiscos de bens de criados do Conde de Seia, Enrique Manuel de Vilhena, tio e apoiante de Juan I Trastâmara ${ }^{35}$, começando em 6 de maio com os bens em Cascais de seu criado João Afonso, que beneficiaria Rodrigo Alvares de Morais, um também criado, mas do aliado do Mestre, Fernando Alvares Pereira $^{36}$. Em outro documento, de 3 de julho, novo confisco ao mesmo Joáo Afonso, beneficiando um seu homônimo, manteiro dos cavaleiros do rei D. Fernando, servidor do rei anterior que teria permanecido no reino português e escolhera apoiar o Mestre ${ }^{37}$. O Conde Enrique Manuel, antes mesmo do cerco, já tinha dado voz, em Sintra, por Juan I, com muitas gentes, "com que o bem podia deffemder" 38 ação que justificaria os dois últimos confiscos de seu fiel criado e, inclusive, o seu próprio ${ }^{39}$. E, ainda, o de outro seu criado, Gonçalo Teixeira, privado de seus bens em Sintra, a 2 de outubro, a favor de Fernão Vasques, vassalo de D. João ${ }^{40}$. Os Teixeira faziam parte do círculo de fiéis e servidores diretos do Conde Vilhena, e seu confisco, assim como dos outros mencionados, minavam internamente a resistência às

\footnotetext{
${ }^{34}$ João Gonçalves da Teixeira, em carta de 4 de março de 1384, já era apontado como em desserviço (Chanc. DJI, 1. I, f. $17 \mathrm{v}-18$ e f. 23).

${ }^{35}$ Após a morte de D. Fernando, o Conde Enrique Manuel de Vilhena lideraria a fracassada tentativa de pedido de arraial por Da. Beatriz, em Lisboa. Uma continuidade mais que lógica após todo seu esforço diplomático para implementar o casamento da Infanta portuguesa com seu sobrinho Juan I de Castela (LOPES, 1966, p. 130 e p. 484).

${ }^{36}$ Bens em Sassoeiros e Charneca em Cascais (Chanc. DJI, l. I, f. 20 e v). Fernando, irmão do Condestável e alcaide de Elvas desde fevereiro de 1382, após uma hesitação inicial, em inícios de 1384, é referido no cerco de Lisboa, lutando ao lado do Mestre (LOPES, 1991, p. 130; 217-218 e 366-368).

${ }^{37}$ Bens em Cascais (Chanc. DJI, l. I, f. 17).

${ }^{38}$ Em outra parte da Crônica refere-se que ele defendia Sintra com cem lanças (LOPES, 1991, p. 139; 379). Findo o cerco sobre Lisboa, em início de setembro, o Conde Vilhena seria mantido, por ordem de Juan I Trastâmara, como alcaide e fronteiro de Sintra, vila que o Mestre não conseguira tomar (LOPES, 1991, p. 328 e 351-352).

${ }^{39}$ Martim Vasques da Cunha receberia, em 21 de maio de 1384, os bens do referido Conde e os manteria até 1394

(Chanc. DJI, 1. I, f. 19v e f. 58v e 1. II, f. 94v-95).

${ }^{40}$ Chanc. DJI, l. I, f. 64.
} 
forças de Avis ${ }^{41}$. Além disso, o reconhecimento de D. João, em 6 de outubro, como Regedor do reino, e a partida do rei castelhano e seus apoiantes em 14 do mesmo mês, fortalecia a posiçấo portuguesa frente a essas localidades acéfalas dos alcaides e autoridades apoiantes dos Trastâmara (LOPES, 1991). Mas, sem dúvida, alguns homens criados pelo Conde teriam sido um alvo mais direto dos confiscos, nem tanto por sua posição no conflito, mas certamente pela situação geográfica de seu patrimônio. A Estremadura, Ribatejo e Alto Alentejo seriam, nesse contexto, o centro das açôes militares, coincidindo com a área de influência patrimonial de Enrique Manuel de Vilhena, e, no caminho entre a fronteira, Lisboa sitiada e arredores, o que parece ter sido um dos fatores a se considerar nesse foco de confiscos ao Conde de Seia e seus criados.

Outro caso de confisco neste mesmo eixo geográfico, que atinge criados de um nobre que se opóe ao Mestre, seria o de Joáo do Couto, criado por Joáo Afonso Teles, Conde de Barcelos, a 14 de junho, devido ao seu apoio prestado ao rei de Castela, junto a quem se encontrava o Conde e certamente o seu criado ${ }^{42}$. Os bens de João do Couto em Lisboa seriam transferidos para o primo daquele que o criara, Mem Rodrigues de Vasconcelos ${ }^{43}$, nobre fiel à causa de Avis. O mesmo Mem Rodrigues de Vasconcelos, no fim do cerco, em 10 de setembro, receberia também os bens, em Lisboa, de Lopo Garcia, um criado de Gonçalo Tenreiro que andava em desserviço ${ }^{44}$. Tenreiro fora capitão da frota portuguesa no reinado anterior e próximo do almirante à época, João Afonso Teles (LOPES, 1966, p. 347; 352; 427 e 435), e torna-se interessante destacar que a anterior proximidade desses dois nobres repercutiria na penalidade imposta aos seus criados em benefício do mesmo nobre fiel ao Mestre.

A 20 de setembro, outro documento apresenta-nos um criado do Comendador-mor da Ordem de Avis, Vasco Porcalho, de nome Álvaro Nunes, que perdera seus bens em Avis e fronteira para um outro criado, mas do Mestre, Pero Colaço ${ }^{45}$. Os dois nobres, membros da Ordem Militar de Avis, haviam partilhado anteriormente a esse contexto de quebra dinástica, os ambientes da Corte régia no reinado de $\mathrm{D}$. Fernando e haviam sido vítimas comuns de uma trama da rainha, na qual Vasco Porcalho e outros membros da sua Ordem teriam supostamente denunciado um plano de traição arquitetado pelo Mestre de Avis. Uma acusação que acabava por envolver falsamente toda a coletividade avisina e definiu uma franca hostilidade de Vasco

\footnotetext{
${ }^{41}$ Para além do âmbito dos criados do Conde, observamos o confisco a outros seus fiéis, um seu escudeiro, Fernão Gonçalves, em 15 de setembro de 1384 (Chanc. DJI, l. I, f. 44v), e seu escrivão, Gonçalo Esteves de Cascais, a 14 de outubro de 1384 (Chanc. DJI, 1. 1, f. 58).

${ }^{42}$ João Afonso Teles, Conde de Barcelos e irmáo de Leonor Teles, em fins de 1383, acompanha o Mestre, juntamente com seus dependentes, pelas ruas de Lisboa (LOPES, 1966, p. 446-448, e, ainda, ARNAUT, 1960, v. 2, p. 366-369; 376-379 e 385-387; LOPES, 1991, p. 37-83; 149; 332 e 383; LOPES, 1990, p. 76; 86-88; 94; 102-105; 117-119 e Chanc. DJI, 1. I, f. 27 e v).

${ }^{43}$ Confisco sofrido juntamente com João Afonso, aio do dito Conde (Chanc. DJI, l. I, f. 13v). O beneficiado era filho de Gonçalo Mendes de Vasconcelos, que, apesar de certa indecisão inicial, promoveria resistência em Coimbra às forças invasoras castelhanas.

${ }^{44}$ Chanc. DJI, 1. 1, f. 49.

${ }^{45}$ Chanc DJI, 1. 1, f. 56 v.
} 
frente à rainha e a seu irmão, o Conde de Barcelos ${ }^{46}$, o que não foi suficiente para movê-lo à fidelidade ao Mestre de Avis após 1383, como esse documento bem o comprova, manifestando clara cisão interna da Ordem Militar de Avis.

Prosseguindo na análise, vemos que os confiscos dos criados de traidores da causa portuguesa continuam no mês seguinte e, em 18 de novembro, Fernão Mateus, criado de um morador de Lisboa seria confiscado em seus bens na cidade em benefício de um outro criado, mas do Mestre chamado Diogo da Rosa ${ }^{47}$.

Já em relação ao benefício de criados de aliados do Mestre encontramos, a 20 de setembro, Vasco Vicente, criado de Nuno Alvares Pereira, que receberia os bens de um escrivão da correição da Estremadura, Álvaro Gonçalves ${ }^{48}$, que andava em companhia do rei de Castela em sua saída do reino ${ }^{49}$. Observamos aqui o único caso de benefício a um criado de aliado do Mestre que não resulta de confisco de criado de seus traidores.

Como vimos, as transferências de bens neste eixo passam a envolver o confisco a criados de nobres de alta condição, ricos-homens e os beneficiários também contam com representantes da ordem nobiliárquica, apoiantes do Mestre, especialmente em setembro de 1384 quando o cerco castelhano à cidade portuguesa seria levantado e o Regedor parece sentir-se mais seguro em suas próprias pretensôes.

Do ponto de vista dos confiscados, percebe-se que a penalização imposta aos nobres em desserviço tem ecos nos seus criados, assim, a rede de vinculaçôes senhoriais parece influenciar a escolha dos confiscados que sofreriam a pena devido à fidelidade aos seus criadores em detrimento da fidelidade à causa portuguesa, correlação que, na grande maioria dos casos analisados, parece ser procedente.

Assim, neste eixo, observamos nove documentos dentre os 31 analisados, num lapso que vai de 30 de março a 18 de novembro de 1384 . Dos oito casos analisados, três envolvem confisco de criados de opositores de Avis, beneficiando outros três indivíduos também identificados como criados, dois do Mestre e um de seu aliado Pereira ${ }^{50}$. Linhagem que ainda teria outro criado beneficiado com os bens de um traidor lisboeta que não é declarado criado de outrem, aumentando para quatro os criados de aliados que recebem benefício.

\footnotetext{
${ }^{46}$ Vasco Porcalho, numas justas promovidas pelo rei D. Fernando teria combatido um nobre fiel ao Conde de Barcelos (LOPES, 1966, p. 266; 404-410).

${ }^{47}$ Criado do morador de Lisboa, Vasco Afonso Carregeira, bens na mesma cidade e em outros lugares (Chanc. DJI, 1. 1, f. 66).

${ }^{48}$ Devemos evitar confundi-lo com Álvaro Gonçalves, vedor da fazenda no reinado de D. Fernando e, depois de 1386 ou 1388, já de D. João I (HOMEM, 1990, p. 275-279; HOMEM, 1984/85, p. 53-68; GOMES, 1994, p. 273).

${ }^{49}$ Chanc. DJI, 1. 1, f. 44 v.

${ }^{50}$ Joáo Afonso e Rodrigo Alvares de Morais, criado dos Pereira (Ibidem, 1.1, f. 20v); Álvaro Nunes e Pero Colaço (Chanc. DJI, 1. I, f. 56v) e Fernão Mateus e Diogo da Rosa (Chanc. DJI, l. I, f. 66). Pero Colaço e Diogo da Rosa engrossam o número de criados do Mestre, mas não são analisados no primeiro subitem por seus benefícios resultarem de confisco de terceiros identificados igualmente como criados e inimigos do Mestre, o que justifica a sua inserção neste terceiro subitem e não no primeiro, que trata dos beneficiados com bens daqueles que não foram criados por outrem.
} 
Note-se a concentração de três confiscos sobre dois criados do Conde de Seia, rede que se amplia quando envolve um Teixeira fiel dos Vilhena e a fonte de sua aliança, os Teles, sofrendo confisco de um seu criado e outro de seu fiel, da linhagem Tenreiro. Percebemos que os vínculos de sangue, vassalidade e criação trabalham de forma uníssona e distributiva na construção de fortes e perenes redes de apoio nesse contexto. Por outro lado, os núcleos de fidelidade colidem entre si, como observamos na quase completa maioria dos casos deste eixo em que criados de inimigos do Mestre são confiscados, beneficiando os seus próprios criados. E ainda percebemos o acirramento dessa tensão interna no documento que manifesta uma cisão no interior da Ordem de Avis que afastaria o Mestre do Comendador-mor. Lembramos que, no primeiro segmento de análise deste trabalho, vimos que, nesse mesmo interstício temporal, apenas um criado da Ordem de Avis estaria com o Mestre em fevereiro de $1384^{51}$ e, em setembro, um criado do Comendador da mesma Ordem seria confiscado por estar em desserviço. Elementos que quando conjugados manifestam a pouca confiança da própria Ordem de Avis na empreitada do seu Mestre.

\section{Conclusóes}

As análises relativas aos criados entendidos como parte da primigênia sociedade política do Mestre de Avis nos trouxeram conclusôes de natureza sócio e geopolítica e, ainda que nosso recorte nos leve até 31 de agosto de 1385, depois de 12 de janeiro desse ano não encontramos qualquer outra menção a indivíduos na condição de criados por alguém. Detectaram-se três picos de doaçóes e respectivos confiscos, em março, maio e setembro de $1384^{52}$ relacionados à instalação e posterior liberação do cerco a Lisboa.

A criação previa, antes de tudo, uma fidelidade pouco definida em suas formas de cumprimento, mas, ainda assim, esperada e forte, como vimos, em todos os casos analisados. A fidelidade assumia, naturalmente, muitas formas nessas realidades medievais, náo sendo limitadas apenas ao vínculo vassálico, e essa forma de fidelidade doméstica gerada pela criatio seria muito rica em seu potencial de aplicação, especialmente em um contexto sociopolítico conturbado como este ora analisado. Enquanto os vínculos feudo-vassálicos poderiam se multiplicar exponencialmente a partir de um indivíduo, causando, por vezes, conflito jurisdicional, a criatio apresentava-se mais restrita no âmbito dos envolvidos na relação, entre aquele que cria e o que é criado, antecedendo e, quiçá, reforçando uma posterior relaçáo de vassalidade. Nos três eixos analisados conseguimos perceber que o vínculo da criação direcionou as opçóes dos envolvidos nesse contexto de 1384, prioritariamente no sentido da conservação da fidelidade original, seja ao Mestre, a seus aliados ou seus inimigos. Neste

\footnotetext{
${ }^{51}$ Vasco Eanes (Chanc. DJI, 1. I, f. 1 v).

${ }^{52}$ Vide anexos, Quadro 1 e Figura 1.
} 
último caso, observa-se ainda melhor essa tendência dos criados de opositores do Mestre de manterem-se fiéis às suas referências primeiras de fidelidade e serviço, a ponto de suplantar o ônus da fuga e confisco de seus benefícios em terras portuguesas, confiantes, em sua opção de resistência externa.

Outro aspecto dessa contrapartida de benefício à manutenção da fidelidade consiste em que os bens doados pelo rei anterior sáo reconhecidos ou suspensos pelo Mestre de Avis, antes de sua eleição, com o mesmo sentido de posse régia que havia tido D. Fernando, assumindo para si o monopólio das transferências de bens em sua plena competência.

Assim, ao analisarmos esses casos a partir da ótica dos beneficiados percebemos que tais açôes concessivas régias se concretizavam exclusivamente a partir do confisco de terceiros, daí entendermos essas iniciativas como transferência de bens. O vínculo propiciado pela criatio, preexistente a esse contexto em análise, que se fortalece com a doação em detrimento da base patrimonial de um indivíduo ou grupo de indivíduos que haviam feito uma outra opção de fidelidade, resultaria obrigatoriamente em uma duplicidade de efeitos: por um lado, fidelidade, e, por outro, oposição ou resistência à fonte concessora. Esses efeitos colaterais do pagamento de fidelidade aos criados fiéis parecem minimizados, na documentação, seja pela emergência imposta pelas condiçóes contextuais, seja pelo fato de os bens auferidos estarem em máos de acusados de desserviço que se encontravam ausentes do reino português.

Prosseguindo nessa senda, percebemos que a condição de traição estava ainda associada com a traição a seu senhor natural, conservando uma dimensão personalista de vinculação, fosse vassálica, de criação ou ambas. No entanto, quando um indivíduo criado por outrem fosse acusado em termos individuais, ainda que em muitos casos sofresse a influência do partidarismo adotado por aquele a quem devia a criatio, tal fato não o eximia de uma condenação jurídica e penalização de cunho pessoal. Assim, a natureza personalista do vínculo náo determinava a opção do criado nem eximia a sua responsabilidade sobre seus atos ou decisões.

A natureza dos bens, móveis e de raiz, pouco identificados nos documentos, em geral se encontram dentro ou próximo às cidades e a entrega de lugares ao invasor ou o conselho para tanto era uma das razóes para o confisco dos indivíduos, em todos os casos, referidos como ausentes do território onde detinham seus benefícios. Já em relação à localização dos bens que seriam objeto de transferência, constata-se que se circunscrevem ao largo da área de instalação do próprio Mestre, concentrando-se na região da Estremadura portuguesa, Ribatejo e Alto Alentejo ${ }^{53}$, regióes nas quais, a partir de Lisboa cercada até a fronteira, desenvolviam-se constantes açôes bélicas de resistência ao invasor. Dois polos, Lisboa, onde se encontrava sitiado o Mestre e as regióes à volta de Avis de influência direta da sua Ordem, onde seus antigos criados parecem ter permanecido, sendo aí beneficiados.

\footnotetext{
${ }^{53}$ Vide anexos, Figura 1. Excetuam-se neste caso as doaçôes na região da Beira, Guarda e Covilhã ligada às movimentações de invasão castelhana no reino.
} 
Por fim, chegamos à conclusão de que, de janeiro de 1384 a janeiro de 1385, o universo mais amplo de indivíduos envolvidos na condição de criados por terceiros e também o mais alargado temporalmente corresponde ao primeiro eixo de análise, o dos criados diretos do Mestre de Avis, em franca defasagem com os criados da Ordem, dos reis anteriores ou mesmo dos seus aliados. Fica bem clara, nesse ponto, a sua opção de privilegiar num primeiro momento, seja por falta de alternativas, seja por segurança, na iminência de um cerco que sofreria pessoalmente, os criados mantidos em seu círculo de fidelidade direta, os quais comporiam, assim, importante círculo de fiéis. Criados que seriam futuros oficiais de sua Casa e administração, alguns também seus futuros vassalos, vinculados desde a infância ao Mestre de Avis, esse universo compósito do ponto de vista social seria coligado e movido pela amizade e privança a seu criador, formando uma rede de apoio fundamental ao projeto de ascensão e construção de legitimidade da nova dinastia de Avis.

\section{Fontes documentais}

ARQUIVOS NACIONAIS / TORRE DO TOMBO. Chancelaria de Fernando. Disponível em: https://digitarq.arquivos.pt/details?id=3813657. Último acesso em: 6 mar. 2019. ARQUIVOS NACIONAIS / TORRE DO TOMBO. Chancelaria de D. João I. Disponível em: https://digitarq.arquivos.pt/details?id=3813662. Último acesso em: 6 mar. 2019. ARQUIVOS NACIONAIS / TORRE DO TOMBO. Chancelaria de D. Pedro I. Disponível em: https://digitarq.arquivos.pt/details?id=3813653. Último acesso em: 6 mar. 2019.

\section{Referências}

ALMEIDA, Cybele Crossetti de. Uma introdução ao método prosopográfico: fontes e questóes para pesquisa. In: PINTO, C. R. J.; GUAZZELLI, C. A. B. (orgs.). Ciências humanas: pesquisa e método. Porto Alegre: Editora da Universidade, UFRGS, 2009.

ARNAUT, S. Dias. A crise nacional dos fins do século XIV: a sucessão de D. Fernando. Coimbra: Instituto de Estudos Históricos Dr. António de Vasconcelos, 1960, 2 v.

AURELL, Martin (org.). Le médiéviste et la monographie familiale: sources, méthodes et problematiques. Turnhout, Bélgica: Brepols, 2001.

AUTRAND, Françoise (org.). Prosopographie et genese de l'État Moderne. Paris: Centre National des Lettres e CNRS, 1986.

CAETANO, Marcello. A crise nacional de 1383-1385. Subsidios para o seu estudo. Lisboa: Verbo, 1985. 
FERNANDES, Fátima Regina. A fronteira luso-castelhana medieval, os homens que nela vivem e o seu papel na construção de uma identidade portuguesa. In: FERNANDES, Fátima Regina (org.). Identidades e fronteiras no Medievo Ibérico. Curitiba: Juruá Editora, 2013.

FERNANDES, Fátima Regina. As crônicas e as chancelarias régias: a natureza e os problemas de aplicação das fontes medievais portuguesas. Revista Ágora, Vitória, v. 16, p. 77-94, 2012. Disponível em http://periodicos.ufes.br/agora/article/view/5017. Acesso em 10 fev. 2019. FERNANDES, Fátima Regina. Do pacto e seus rompimentos: os Castros Galegos e a condiçáo de traidor na Guerra dos Cem Anos. Curitiba: Editora Prismas, 2016.

FERNANDES, Fátima Regina. Portugal 1385, quando um reino fez seu rei. Jundiaí (SP): Paco Editorial, 2018. Disponível em: https://www.amazon.com.br/s/?search-alias=digital-text\&f ieldkeywords=9788546213689; https://play.google.com/store/search?q=9788546213689; https://www.kobo.com/br/pt/ebook/portugal-1385-quando-um-reino-fez-seu-rei.

FERNANDES, Fátima Regina. Sociedade e poder na Baixa Idade Média portuguesa. 1. ed. Curitiba: Editora da Universidade Federal do Paraná, 2003.

GENET, Jean-Philippe. La genèse de l'État Moderne: genèse d'un programme de recherche. In: COELHO, Maria Helena da Cruz; HOMEM, Armando Luís de Carvalho (orgs.). A gênese do Estado Moderno no Portugal tardo-medievo. Lisboa: Universidade Autônoma de Lisboa, 1999, p. 21-25.

GERBET, Marie-Claude. La nobleza en la Corona de Castilla. Sus estructuras sociales en Extremadura (1454-1516). Cáceres: Institucion Cultural "El Brocense", 1989.

GOMES, Rita Costa. A Corte dos reis de Portugal no final da Idade Média. Lisboa: DIFEL, 1995.

GOMES, Saul da Costa. Corregedores da Comarca da Extremadura e suas intervençóes no Concelho de Leiria na Idade Média. Coimbra, 1994.

GRASSOTTI, Hilda. Las instituciones feudo-vassaláticas en León y Castilla. Spoleto: Centro Italiano di Studi sull'Alto Medioevo, 1969.

HEINZ, Flávio (org). Por outra história das elites. Rio de Janeiro: Editora da FGV, 2006.

HOMEM, Armando Luís de Carvalho. O Desembargo Régio (1320-1433). Porto: Centro de História da Universidade do Porto-INIC, 1990.

HOMEM, Armando Luís de Carvalho. Um percurso singular no Desembargo régio Álvaro Gonçalves (1368-1406). Estudos Medievais, Porto, n. 5/6, p. 53-68, 1984/85.

LOPES, Fernão. Crónica de D. Pedro I. Porto: Civilização, 1965.

LOPES, Fernão. Crónica de D. Fernando. Porto: Civilização, 1966.

LOPES, Fernão. Crónica de D. João I. la p. Barcelos-Porto: Civilização, 1991.

LOPES, Fernão. Crónica de D. João I, 2a p. Barcelos-Porto: Civilização, 1990. 
MATTOSO, José. Identificação de um país. Lisboa: Editorial Estampa, 1985, 2v.

MATTOSO, José; SOUSA, Armindo de (orgs). História de Portugal: a monarquia feudal (1096-1480). Lisboa: Círculo de Leitores, 1993, v. 2.

MORENO, Humberto Baquero. Os itinerários de el-Rei Dom João I. Lisboa: Instituto de Cultura e Língua Portuguesa, 1988.

MOXÓ Y ORTIZ DE VILLAJOS, Salvador de. De la Nobleza Vieja a la Nobleza Nueva. Cuadernos de História, Madrid, n. 3, p. 1-210, 1969.

RUSSELL, Peter Edward. João Fernandes Andeiro at the Court of John of Lancaster: 13711381. Revista da Universidade de Coimbra, Coimbra: Faculdade de Letras da Universidade de Coimbra, n. XIV, p. 20-30, 1940.

SOUSA, António Caetano de. História genealógica da Casa Real Portugueza. Coimbra: Academia Real, 1735, t. III.

VENTURA, Leontina. A nobreza de Corte de Afonso III. Coimbra: Faculdade de Letras da Universidade de Coimbra, 1992, 2v.

VIEGAS, Valentino. Cronologia da revolução de 1383-1385. Lisboa: Editorial Estampa, 1984.

VITERBO, Fr. J. de Santa Rosa de. Elucidário das palavras, termos e frases que em Portugal antigamente se usaram e que hoje regularmente se ignoram. Porto: Civilização, 1962-1965, 2v. 


\section{Quadro 1}

As localidades dos bens concedidos aos criados (janeiro 1384 a janeiro 1385$)^{54}$

\begin{tabular}{|c|c|c|c|c|c|c|c|c|c|c|c|c|c|c|c|}
\hline & & $\begin{array}{c}\text { Jan } \\
\mathbf{1 3 8}\end{array}$ & $\begin{array}{c}\text { Fev } \\
\mathbf{1 3 8 4}\end{array}$ & $\begin{array}{c}\text { Mar } \\
\mathbf{1 3 8 4}\end{array}$ & $\begin{array}{c}\text { Abr } \\
\mathbf{1 3 8 4}\end{array}$ & $\begin{array}{c}\text { Maio } \\
\mathbf{1 3 8 4}\end{array}$ & $\begin{array}{l}\text { Jun } \\
\mathbf{1 3 8 4}\end{array}$ & $\begin{array}{c}\text { Jul } \\
\mathbf{1 3 8 4}\end{array}$ & $\begin{array}{c}\text { Ago } \\
\mathbf{1 3 8 4}\end{array}$ & $\begin{array}{c}\text { Set } \\
\mathbf{1 3 8 4}\end{array}$ & $\begin{array}{c}\text { Out } \\
\mathbf{1 3 8 4}\end{array}$ & $\begin{array}{c}\text { Nov } \\
\mathbf{1 3 8 4}\end{array}$ & $\begin{array}{c}\text { Dez } \\
\mathbf{1 3 8 4}\end{array}$ & $\begin{array}{c}\text { Jan } \\
\mathbf{1 3 8 5}\end{array}$ & $\begin{array}{c}\text { Total de } \\
\text { doaçós }\end{array}$ \\
\hline 1 & Colares & 1 & & & & & & & & & & & & & 1 \\
\hline 2 & Évora & & 1 & & & & & & & & & & & & 1 \\
\hline 3 & Santarém & & & 3 & & 1 & & & & 3 & & & & & 7 \\
\hline 4 & Portalegre & & & 1 & & & & & & & & & & & 1 \\
\hline 5 & $\begin{array}{c}\text { Castelo de } \\
\text { Vide }\end{array}$ & & 1 & & & & & & & & & & & 1 \\
\hline 6 & Monforte & & & 1 & & & & & & & & & & & 1 \\
\hline 7 & Lisboa & & & 1 & & 1 & 1 & & & 1 & 1 & & & & 5 \\
\hline 8 & Guarda & & & & 1 & & & & & & & & & & 1 \\
\hline 9 & Alter do Chão & & & & & 1 & & & & & & & & & 1 \\
\hline 10 & Campo Maior & & & & & 1 & & & & & & & & & 1 \\
\hline 11 & Avis & & & & 1 & & & & 1 & & & & & 2 \\
\hline 12 & Cascais & & & & 1 & & 1 & & & & & & & 2 \\
\hline 13 & Torres Vedras & & & & & & & & 1 & & & & & 1 \\
\hline 14 & Almada & & & & & & & & & 2 & & & & & 2 \\
\hline 15 & Covilhã & & & & & & & & & 2 & & & & & 2 \\
\hline 16 & Sintra & & & & & & & & & 1 & & & & 1 \\
\hline
\end{tabular}

\footnotetext{
${ }^{54}$ Os números sequenciais à esquerda correspondem às localidades marcadas no mapa a seguir.
} 


\section{Figura 1}

Mapa das localidades referidas nas doaçóes a criados (janeiro 1384 a janeiro 1385)

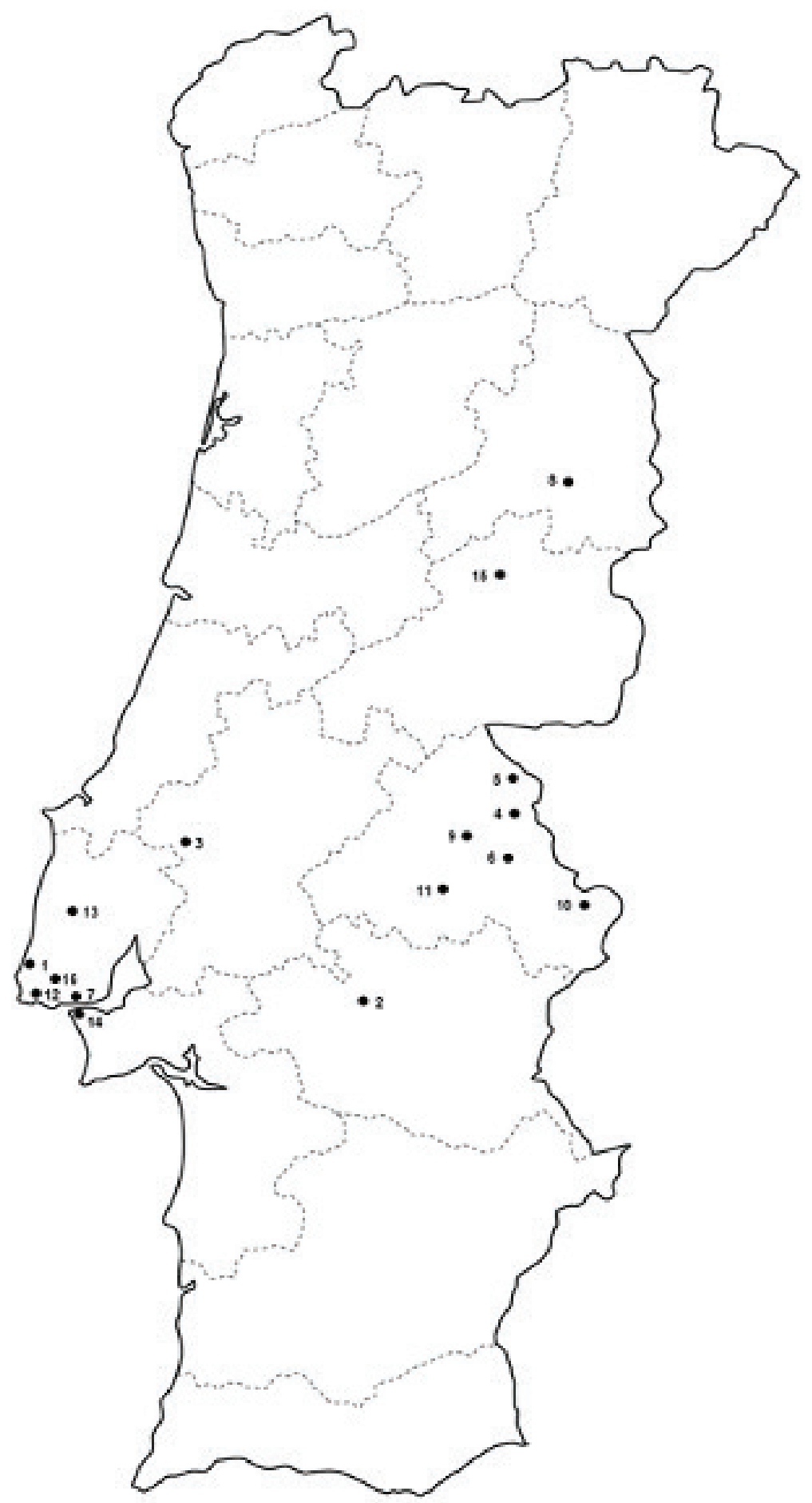

